\title{
Effects of Fluctuating Soil Temperature and Water Potential on Sclerotia Germination and Apothecial Production of Sclerotinia sclerotiorum
}

\author{
A. L. Mila and X. B. Yang, Department of Plant Pathology, Iowa State University, Ames 50011
}

\begin{abstract}
Mila, A. L., and Yang, X. B. 2008. Effects of fluctuating soil temperature and water potential on sclerotia germination and apothecial production of Sclerotinia sclerotiorum. Plant Dis. 92:78-82.

The effects of fluctuating soil temperature and water potential on sclerotial germination and apothecial production by Sclerotinia sclerotiorum were investigated in growth chamber experiments. In the temperature experiments, temperature fluctuations of $4,8,12$, and $16^{\circ} \mathrm{C}$ around a median of $20^{\circ} \mathrm{C}$, and a constant of $20^{\circ} \mathrm{C}$, were tested. Daily temperature fluctuations of $8^{\circ} \mathrm{C}$ resulted in highest levels of sclerotial germination and apothecial production. The earliest appearance of apothecia occurred in the $8^{\circ} \mathrm{C}$ fluctuation treatment, 24 days after the start of the experiment. Sclerotia in the $12^{\circ} \mathrm{C}$ fluctuation treatment germinated last; its first sclerotium germinated 44 days after experiment initiation. For the soil water potential experiments, constant saturation (approximately $-0.001 \mathrm{MPa}$ ) and three levels of soil water potential fluctuation from saturation-"low" ( -0.03 to $-0.04 \mathrm{MPa})$, "medium" $(-0.06$ to $-0.07 \mathrm{MPa})$, and "high" $(-0.09$ to $-0.1 \mathrm{MPa}$ - were tested. Constant saturation yielded the highest number of germinated sclerotia and apothecia. All soil water potential fluctuations were detrimental to sclerotial germination and apothecial production, with sclerotial germination under fluctuating moisture conditions less than a tenth of that occurring under constant saturation. The first sclerotium in the constant saturation treatment germinated in 35 days; however, 76 days were required in the high soil water potential fluctuation treatment.
\end{abstract}

The host range of Sclerotinia sclerotiorum (Lib.) de Bary includes more than 360 species in 62 plant families (19). $S$. sclerotiorum survives in the soil as sclerotia for long periods. Epidemics are initiated by ascospores released from apothecia produced by sclerotia. Mycelial infection of plant tissues has been observed but occurs rarely under natural conditions (2). Thus, ascospores are considered to be the primary source of inoculum. Generally, only sclerotia in the top 2 to $3 \mathrm{~cm}$ of the soil profile are functional, because apothecia with stipes longer than $3 \mathrm{~cm}$ are rarely produced under field conditions (2). The most favorable site for infection is a senescent flower at lower nodes; however, infection may occur in leaves and nodes as well (10).

Several factors influence carpogenic germination of sclerotia of S. sclerotiorum, prolonged low soil moisture being the most common limiting factor $(1,10,16)$. Continuous saturation is required for apothecial development, and even a slight moisture tension prevents apothecial for-

Corresponding author: A. L. Mila

E-mail: almila@ncsu.edu

Current address of A. L. Mila: Department of Plant Pathology, North Carolina State University, Raleigh 27606.

Accepted for publication 21 August 2007.

doi:10.1094/PDIS-92-1-0078

(C) 2008 The American Phytopathological Society mation (2). Duniway et al. (8) demonstrated that formation of initials stops at matric potential -0.008 to $-0.038 \mathrm{MPa}$, whereas there is no growth of mature apothecia at matric potentials below -0.05 $\mathrm{MPa}$. It has been shown that preconditioned sclerotia require matric potentials at or above -7.5 bars for about 10 days or longer to produce apothecia (17). However, apothecia may emerge after a period of intense rainfall even though drying may already have occurred (3). Hartill (13) did not find apothecia of $S$. sclerotiorum during prolonged dry periods, but apothecia appeared within 1 week of heavy rain. Light intensity is also an important factor; more apothecia were produced under high light intensity (120 to $130 \mathrm{~mol} \mathrm{~m}^{-2} \mathrm{~s}^{-1}$ ) than low intensity (80 to $90 \mathrm{~mol} \mathrm{~m}^{-2} \mathrm{~s}^{-1}$ ) (23).

Temperatures between 10 and $20^{\circ} \mathrm{C}$ seem to be favorable for sclerotia germination, although large variation in the optimum temperature requirements has been reported (18). Abawi and Grogan (2) suggested that temperature is an unlikely limiting factor for white mold epidemics in most bean-producing areas of the United States, but a study (24) conducted in the north-central region indicated that summer air temperature rather than precipitation was the limiting factor for soybean Sclerotinia stem rot epidemics in this region of the United States. In another study (23) conducted with a population of sclerotia collected in Iowa, a substantial number of apothecia was produced at 25 to $30^{\circ} \mathrm{C}$.
Agronomic practices, by modifying microclimate, affect sclerotia germination and apothecia production. Fewer apothecia have been reported beneath open peanut and bean canopies than under dense canopies $(5,20)$. Sclerotinia stem rot incidence in soybean was greater in narrow planting rows, where canopy is dense, than in wide rows $(11,21)$. Planting date also can be very important. For instance, late summer or early fall seedings of alfalfa are most vulnerable to $S$. trifoliorum because plants are still in the seedling state when ascospores are released; plants seeded in the spring, on the other hand, are not exposed to ascospores until fall and, by then, are less susceptible (22).

Tillage practices also were reported to affect soybean stem rot incidence, with fewer dead plants and apothecia being found in no-tillage fields than in plowed soybean fields (15). In another study (24), soybean stem rot was more prevalent in fields under reduced tillage than under no tillage or conventional tillage. It was suggested that sclerotia in no-tillage fields remain on the soil surface and, thus, are exposed to drying conditions, whereas sclerotia in reduced-tillage conditions are buried at soil depths that are more stable in moisture and temperature levels and are shallow enough to allow apothecial stipes to reach the soil surface (24). Another suggested explanation $(7,9)$ could be the increased activity of soil microorganisms affecting the germination and survival of sclerotia.

Soil moisture and temperature can vary considerably in the top 2 to $3 \mathrm{~cm}$ of soil and are affected by wind velocity, type and density of plant canopy, and management practices such as tillage and row spacing. Buchan (4) and Campbell (6) observed large (up to $15^{\circ} \mathrm{C}$ ) daily temperature fluctuations on the bare soil surface that diminish rapidly within the top $8 \mathrm{~cm}$ of soil depth. F. Workneh and X. B. Yang (unpublished data) observed that soil temperature and moisture varied more on the soil surface than at 5-cm depth and in wide (30 $\mathrm{cm}$ ) soybean planting rows than narrow $(15 \mathrm{~cm})$ ones. They found the smallest soil temperature and water potential fluctuations to occur at 5-cm depth in plots with narrow-row planting, whereas the largest fluctuations were at the soil surface with wide-row planting. Similar observations were made by Kora (14) and Butzler (5).

Although soil moisture and temperature fluctuations occur regularly in soils, their 
effect on S. sclerotiorum sclerotial germination and apothecial production has not been investigated. The objective of the present study was to examine whether fluctuating soil temperature and soil water potential affect sclerotial germination and apothecial production. Results of this study would assist in deriving more definitive explanations of the effect of different cultural practices on sclerotia germination and apothecia production of S. sclerotiorum.

\section{MATERIALS AND METHODS}

Sclerotia selection and preconditioning. Sclerotia were collected in late September 2000 from a soybean field planted to cv. PB239792 near Ackley, IA, that was severely infested with $S$. sclerotiorum. Sclerotia were sorted by size; only similarsize sclerotia (approximately 12 to $14 \mathrm{~mm}$ in length and $2 \mathrm{~mm}$ in diameter) were used in the experiments. Sclerotia were stored in paper bags at room temperature (approximately $20^{\circ} \mathrm{C}$ ) in the dark.

Before each experiment, sclerotia were tested for viability. Fifty sclerotia chosen arbitrarily were hydrated for $45 \mathrm{~min}$ in sterile distilled water, surface sterilized for 30 seconds in $95 \% \mathrm{ETOH}$, air dried, and plated individually on potato-dextrose agar amended with tetracycline and streptomycin, both at $0.15 \mathrm{mg} / \mathrm{ml}$. Mycelial germination was evaluated 7 to 10 days after incubation at $20^{\circ} \mathrm{C}$ on a 12 -h light-and-dark cycle (16). Sclerotia were preconditioned before each experiment by placing 30 to 40 sclerotia on a layer of sterile paper towel saturated with $5 \mathrm{ml}$ of sterile distilled water in a sterile plastic petri plate. The plates were sealed and placed in a refrigerated incubator $\left(5\right.$ to $\left.6^{\circ} \mathrm{C}\right)$ in darkness for 8 weeks.

For each temperature or moisture fluctuation treatment, three replicates were used. Each replicate consisted of a 31-by23-by-11-cm crisper containing $3 \mathrm{~kg}$ of sterilized sand. Sixteen preconditioned sclerotia were placed on the sand surface in each crisper. Six crispers (i.e., two treatments) were placed in a growth chamber (PGW36; Conviron, Pembina, ND) where light intensity was between 160 and $190 \mathrm{~mol} \mathrm{~m}^{-2} \mathrm{~s}^{-1}$ at the level of the crisper covers and 120 to $130 \mathrm{~mol} \mathrm{~m}^{-2} \mathrm{~s}^{-1}$ inside the crispers (23) and set at a 12-h lightand-dark cycle. The experiment for temperature fluctuation was conducted four times (referred to as experiments 1 to 4 ) and for moisture fluctuation three times (referred to as experiments 5 to 7). Each experiment was conducted for 90 days.

Temperature fluctuation experiments. Five daily temperature treatments involving daily fluctuations of $0,4,8,12$, and $16^{\circ} \mathrm{C}$ were investigated. All treatments had a median daily temperature of $20^{\circ} \mathrm{C}$, chosen on the basis of a previous finding that the optimum temperature for sclerotia carpogenic germination was 18 to $20^{\circ} \mathrm{C}$ (23). For the $4,8,12$, and $16^{\circ} \mathrm{C}$ fluctua- tions, temperatures in the sand were alternated from 18 to 22,16 to 24,14 to 26 , and 12 to $28^{\circ} \mathrm{C}$, with minimum temperatures occurring at midnight and maximum temperatures at noon. A constant $20^{\circ} \mathrm{C}$ was used for the nonfluctuating treatment. The 4 and $8^{\circ} \mathrm{C}$ fluctuation treatments were tested in one incubator and the 12 and $16^{\circ} \mathrm{C}$ fluctuations in another one. In each incubator, noon and midnight temperatures were set to the lowest levels on each pair of treatments. For instance, the 18-to-22 and 16 -to- $24^{\circ} \mathrm{C}$ treatments were placed in the same incubator where the noon temperature was set at $22^{\circ} \mathrm{C}$ and the midnight temperature set at $16^{\circ} \mathrm{C}$. The temperatures were raised and lowered between these extremes over 12-h cycles. The higher noon $\left(24^{\circ} \mathrm{C}\right.$ ) and midnight $18^{\circ} \mathrm{C}$ sand temperatures in the same incubator were generated with stepless temperature controllers (Thermolyne type 45500) and heating tapes (122 by $1.3 \mathrm{~cm}, 104 \mathrm{~W}$, Thermolyne/Briskheat; Barnstead International, Dubuque, IA) around the appropriate crispers. The constant-temperature treatment was tested separately in a third incubator. Sand temperatures were recorded constantly with a data logger (CR10; Campbell Scientific, Inc., Logan, UT). Sand in all crispers was kept near saturation (soil water matric potential $\left[\psi_{m}\right]=$ approximately $-0.001 \mathrm{MPa}$ ) for the duration of the experiments.

Moisture fluctuation experiments. Four treatments involving $\psi_{m}$ were investigated, three that fluctuated in differing intensity and duration and one that was kept constantly at saturation $\left(\psi_{m}=\right.$ approximately $-0.001 \mathrm{MPa}$ ) by adding water as needed periodically and sealing the crispers to avoid water evaporation. Initially, sand in all crispers was saturated for 3 days. Subsequently, $\psi_{m}$ was manipulated by drying the sand for 3,5 , and 7 days until $\psi_{m}$ reached -0.03 to $-0.04 \mathrm{MPa}$ (low $\psi_{m}$ fluctuation), -0.06 to $-0.07 \mathrm{MPa}$ (medium $\psi_{m}$ fluctuation), and -0.09 to -0.1 MPa (high $\psi_{m}$ fluctuation), respectively. When the desired $\psi_{m}$ for a treatment was reached, the sand was brought back to saturation. The saturation and low $\psi_{m}$ fluctuation treatments were tested in one same incubator, whereas the medium $\psi_{m}$ fluctuation and high $\psi_{m}$ fluctuation treatments

Table 1. Effects of constant and fluctuating temperature on germination of sclerotia of Sclerotinia sclerotiorum, levels of apothecial production, and rapidity of apothecial production ${ }^{\mathrm{a}}$

\begin{tabular}{lccc}
\hline Treatment range & $\begin{array}{c}\text { Sclerotia } \\
\text { germinated }(\%)\end{array}$ & $\begin{array}{c}\text { No. of apothecia } \\
\text { produced }\end{array}$ & $\begin{array}{c}\text { No. of days for } 50 \% \text { of all } \\
\text { apothecia to be produced }\end{array}$ \\
\hline Constant $\left(20^{\circ} \mathrm{C}\right)$ & 15.6 & 64.3 & 62.5 \\
$18-22^{\circ} \mathrm{C}$ & 16.0 & 79.2 & 57.5 \\
$16-24^{\circ} \mathrm{C}$ & 40.0 & 210 & 59.5 \\
$14-26^{\circ} \mathrm{C}$ & 15.0 & 61.3 & 69.0 \\
$12-28^{\circ} \mathrm{C}$ & 7.8 & 54.5 & 64.5 \\
$\mathrm{LSD}$ & 14.0 & 59.0 & 1.3 \\
$P$ value & 0.002 & 0.0002 & 0.5 \\
\hline
\end{tabular}

${ }^{\mathrm{a}}$ Means of four experiments, each with three replications $(n=16)$.

${ }^{\mathrm{b}}$ Least significant difference. were tested in another. Temperature in the incubators was set at $20^{\circ} \mathrm{C}$. Matric potentials were monitored continuously with Watermark soil moisture blocks (sensor models 257; Campbell Scientific, Inc.) placed $1 \mathrm{~cm}$ under the sand surface. The blocks are accurate between 0 and -0.2 MPa.

Data collection and statistical analysis. Experiments were checked every 3 days for the first appearance of an apothecium, after which new apothesia were counted every 2 days. Apothecia were removed after counting. Percentage of germinated sclerotia, number of apothecia produced, and number of days to $50 \%$ total apothecial production were analyzed for homogeneity of variance with Bartlett's test. No significant differences were found between results of repeated experiments and, therefore, data from the four temperature experiments and from the three moisture experiments were pooled for variance analysis. Furthermore, percentage of germinated sclerotia, number of apothecial production, and number of days to $50 \%$ total apothecial production were examined for normality with the Shapiro-Wilks W test. Percentage of germinated sclerotia and number of apothecia produced in the moisture experiments did not meet the normality assumption and, thus, were transformed using arcsine square root and $\log (x+1)$, respectively, before analysis. Data were analyzed with Generalized Linear Models and Fisher's protected least significant difference test (LSD). Statistical analyses were performed using Statistical Analysis System (version 8.1; SAS Institute, Inc., Cary, NC). In addition, orthogonal contrast analyses were performed on the number of apothecia produced to compare temperature and matric potential fluctuation treatments.

\section{RESULTS}

Viability of the sclerotia used in the experiment was high because myceliogenic germination of sclerotia was at least $98 \%$ in the viability tests. Carpogenic germination of sclerotia, however, was generally low to moderate in all experiments. Under constant saturation and $20^{\circ} \mathrm{C}$, common in all seven experiments, carpogenic germination ranged from 25 to $45 \%$, and there 
was no significant change in the percentage of carpogenic germination of sclerotia over time.

Temperature fluctuation experiments. The highest percentage of germinated sclerotia and the greatest number of apothecia produced occurred in the $8^{\circ} \mathrm{C}$ fluctuation treatment (Table 1). The smaller temperature fluctuations of 4 and $8^{\circ} \mathrm{C}$ triggered higher apothecial production than the larger fluctuations of 12 and $16^{\circ} \mathrm{C}$ and the constant-temperature treatment (Table 2). Orthogonal contrasts indicated that, when all fluctuation treatments were combined in the analysis, their effect on apothecia produced was not significantly different from that in the constanttemperature treatment (Table 2). Half of the apothecia produced appeared within 60 to 69 days after the experiment began regardless of temperature treatment (Table $1)$, but significantly $(P=0.0002)$ more

Table 2. Orthogonal contrasts of five temperature fluctuation treatments for mean numbers of apothecia of Sclerotinia sclerotiorum produced

\begin{tabular}{lccc}
\hline Orthogonal contrast $\left({ }^{\circ} \mathbf{C}\right)^{\mathbf{a}}$ & MS & $\boldsymbol{F}$ value & \multicolumn{1}{c}{$\boldsymbol{P}$} \\
\hline 4 or 8 vs. 12 or 16 & 520 & 5.2 & 0.05 \\
4 vs. 8 & 34,191 & 22.0 & 0.0003 \\
8 vs. 12 & 44,253 & 28.5 & $<0.0001$ \\
8 vs. 16 & $48,360.5$ & 31.1 & $<0.0001$ \\
\hline
\end{tabular}

a Numbers denote temperature fluctuations. Fluctuations of $4,8,12$, and $16^{\circ} \mathrm{C}$ were generated by alternating between midnight and noon temperatures of a constant-temperature $\left(20^{\circ} \mathrm{C}\right)$ treatment and four treatments of 18 and 22,16 and 24,14 and 26 , and 12 and $28^{\circ} \mathrm{C}$, respectively, around a median of $20^{\circ} \mathrm{C}$. The "no-fluctuation" treatment was kept constant at $20^{\circ} \mathrm{C}$.

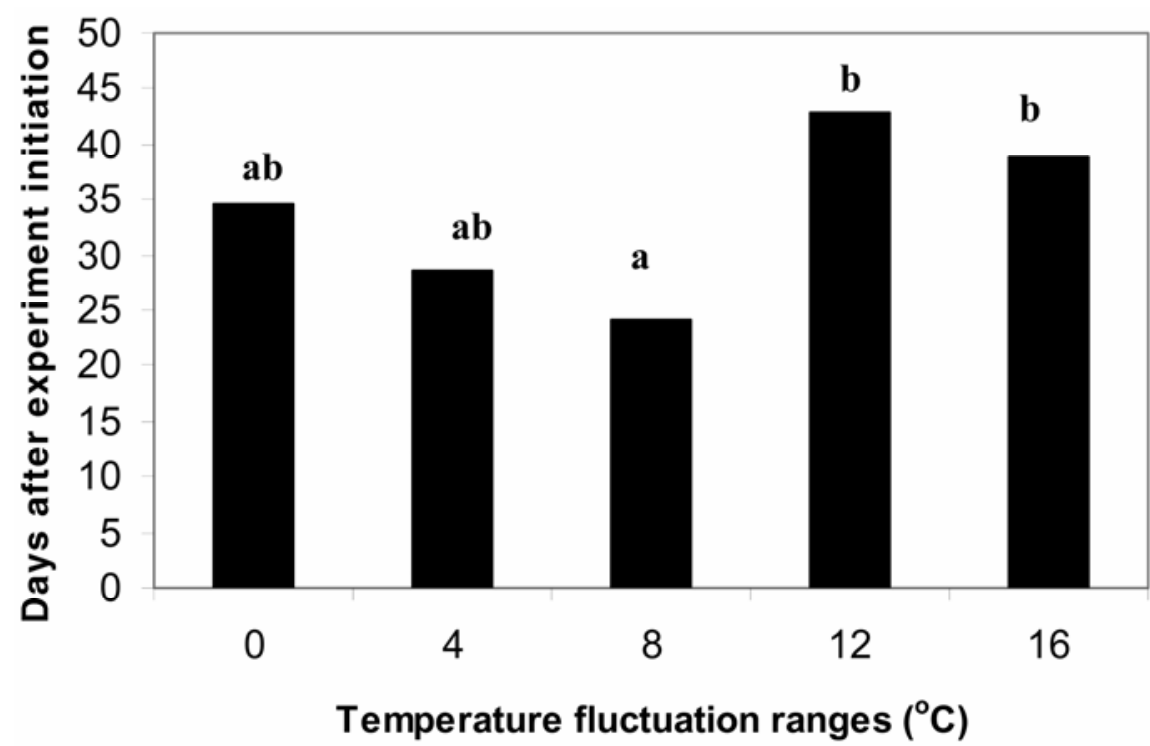

Fig. 1. Days from the beginning of the experiment until the germination of the first sclerotium of Sclerotinia sclerotiorum in the temperature fluctuations experiments. Fluctuations of $4,8,12$, and $16^{\circ} \mathrm{C}$ were generated by alternating midnight and noon temperatures between 18 and 22, 16 and 24, 14 and 26 , and 12 and $28^{\circ} \mathrm{C}$, respectively, around a median of $20^{\circ} \mathrm{C}$. The " $0{ }^{\circ} \mathrm{C}$ fluctuation" treatment was kept constant at $20^{\circ} \mathrm{C}$. Values are means of four experiments. Columns with the same letters are not significantly different from each other as determined by Duncan's multiple range test $(P=0.05)$.

Table 3. Effects of matric potential fluctuations on germination of sclerotia of Sclerotinia sclerotiorum, levels of apothecial production, and rapidity of apothecial production ${ }^{\mathrm{a}}$

\begin{tabular}{lccc}
\hline $\begin{array}{l}\text { Matric potential } \\
\text { treatment }\end{array}$ & $\begin{array}{c}\text { Sclerotia germinated } \\
(\boldsymbol{\%})^{\mathbf{b}}\end{array}$ & $\begin{array}{c}\text { No. of apothecia } \\
\text { produced }^{\mathbf{c}}\end{array}$ & $\begin{array}{c}\text { Days to 50\% of total } \\
\text { apothecia produced }\end{array}$ \\
\hline Constant saturation & 17 & 130.3 & 65 \\
Low fluctuation & 2.7 & 7.7 & 72 \\
Medium fluctuation & 1.7 & 7.0 & 79 \\
High fluctuation & 0.7 & 1.7 & 81 \\
LSD & 1.3 & 2.3 & 280.0 \\
$P$ value & 0.012 & 0.02 & 0.026 \\
\hline
\end{tabular}

a Means of three experiments, each having three replications $(n=16)$.

b Statistics were performed on arcsine square root transformed data; reported means represent backtransformed values.

${ }^{c}$ Statistics were performed on $\log (\mathrm{x}+1)$ transformed data; reported means represent back-transformed values.

${ }^{\mathrm{d}}$ Least significant difference.

apothecia developed with an $8^{\circ} \mathrm{C}$ fluctuation than any other temperature treatment. Apothecial production also began earlier in the $8^{\circ} \mathrm{C}$ fluctuation treatment than in the others (Fig. 1), with the first germinated sclerotium in the $8^{\circ} \mathrm{C}$ fluctuation treatment being recorded 24 days after the experiment initiation. The $12^{\circ} \mathrm{C}$ fluctuation treatment had the slowest germination, with the first sclerotium germinating 44 days after the experiment began (Fig. 1).

Moisture fluctuation experiments. The constant-saturation treatment had the highest percentage of germinated sclerotia and the most apothecia produced (Table 3). All of the $\psi_{m}$ fluctuation treatments significantly reduced sclerotial germination and apothecial production compared with the constant saturation treatment (Table 3). The largest reduction occurred in the high $\psi_{m}$ fluctuation $(-0.09$ to $-0.1 \mathrm{MPa})$ treatment (Table 3). Sclerotial germination occurred earliest in the saturation treatment and latest in the high $\psi_{m}$ fluctuation treatment, 35 and 76 days, respectively, after the experiment began (Fig. 2). In the saturation treatment, $50 \%$ of the apothecia were produced within 2 months after experiment initiation, whereas 80 days was required to reach the same level of apothecia production in the medium and high $\psi_{m}$ fluctuation treatments (Table 3). When the constant-saturation and low $\psi_{m}$ fluctuation treatments were combined and compared with orthogonal contrasts to the medium or high $\psi_{m}$ fluctuation treatments, differences $(P<0.01)$ were identified (Table 4$)$.

\section{DISCUSSION}

Although it has been speculated that soil temperature and water potential fluctuations should have an effect on sclerotia germination (2), to our knowledge this epidemiological aspect has not been examined for S. sclerotiorum or other species of the family Sclerotiniaceae. Our results demonstrated that these factors affect the carpogenic germination of sclerotia of $S$. sclerotiorum. Although sclerotia germination and apothecia production occurred over a wide range of soil temperature and moisture conditions, we found small temperature fluctuations and continuous saturation to be most favorable. Temperature fluctuations greater than $16^{\circ} \mathrm{C}$ may be prohibitive to sclerotial germination because few sclerotia germinated when temperatures fluctuated at that level.

Our observations were based on a median daily temperature of $20^{\circ} \mathrm{C}$, a temperature optimum for sclerotia carpogenic germination under saturated soil conditions determined in experiments with a population of sclerotia collected from Iowa (23) that exhibited a very high germination frequency $(95 \%)$. A similar trend was not observed in the present study; percent germinated sclerotia in constant saturation and $20^{\circ} \mathrm{C}$ ranged between 25 and $45 \%$. This range is closer to the percent germi- 
nation reported by Matheron et al. (16) for wet soil and $20^{\circ} \mathrm{C}$ in the western United States. Schwartz (20) reported that sclerotia collected in the fall, as in the present study, had lower carpogenic germination than sclerotia collected in spring.

A wide range of optimum temperature conditions for sclerotial germination of $S$. sclerotiorum has been reported, implying an adaptation of the pathogen in different geographic regions (18). Combinations of different average daily temperatures and moisture conditions have various effects on sclerotia germination (12). Thus, there is a chance that the fluctuation ranges used in the present study might cause different effects on sclerotial germination and apothecial production when applied with different median temperatures and moisture combinations.

Our results suggested that optimum soil water condition for sclerotia germination and apothecia production is saturation ( $\psi_{m}$ $=$ approximately $-0.001 \mathrm{MPa}$ ). These results are in agreement with those of Phillips (18) and Abawi and Grogan (2). The latter observed that continuous moisture for approximately 10 days was required for sclerotia germination and speculated that even slight osmotic stress inhibited germination (2). Similarly, Duniway et al. (8) demonstrated that production of apothecia of S. sclerotiorum was very sensitive to soil matric potential, with the number of initials and mature apothecia being maximal at -0.008 to $-0.038 \mathrm{MPa}$ and the growth of mature apothecia being prevented at matric potentials below -0.05 $\mathrm{MPa}$.

With constant saturation, sclerotia germination began sooner than with any other soil water potential treatment and continued for 60 to 70 days. In our study, $12 \%$ of the apothecia produced by sclerotia exposed to soil water potential fluctuations were produced during the drying period of the treatment. It has been reported that sclerotia subjected to extreme drying at the soil surface did not form apothecia when they subsequently were put in ideal conditions for germination (1). Our study suggests that, after short periods of drying (1 to 4 days), sclerotia may still be able to produce apothecia.

Using the same light-intensity levels employed in this study (160 to $190 \mathrm{~mol} \mathrm{~m}^{-2}$ $\mathrm{s}^{-1}$ at the level of the crisper covers and 120 to $130 \mathrm{~mol} \mathrm{~m}^{-2} \mathrm{~s}^{-1}$ inside the crispers),

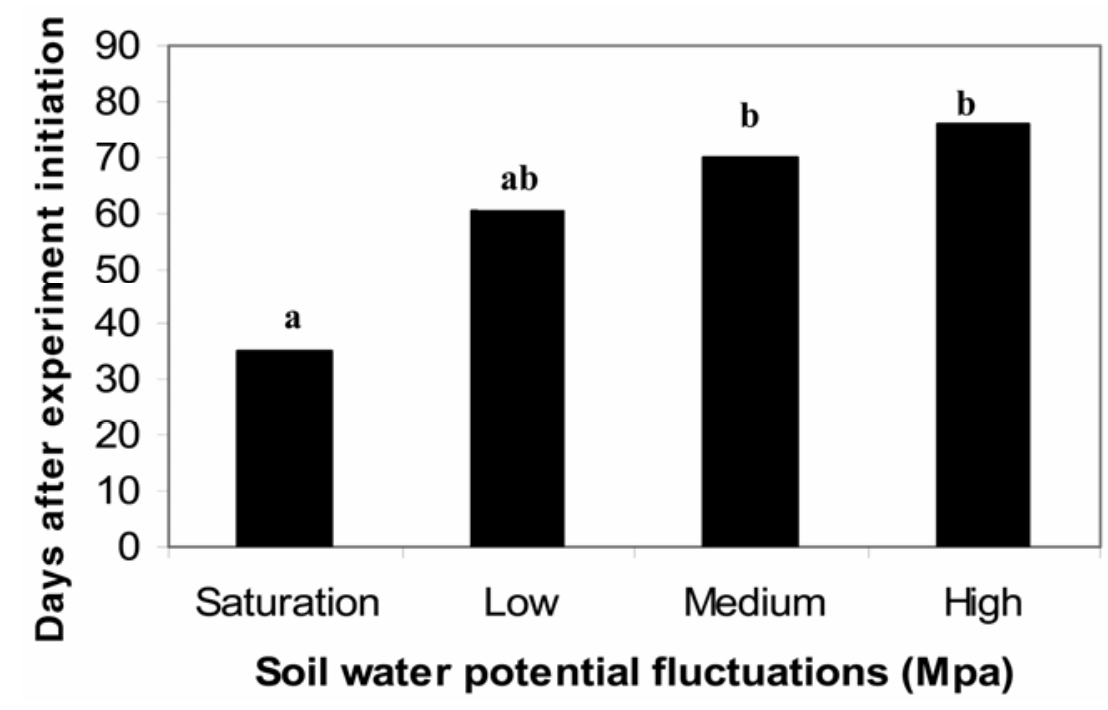

Fig. 2. Days from the beginning of the experiment until the germination of the first sclerotium of Sclerotinia sclerotiorum in the soil water potential fluctuations experiments. Low, medium, and high soil water potential fluctuation treatments were generated by drying sand from saturation for 3,5 , and 7 days until soil water matric potential $\psi_{m}$ reached -0.03 to -0.04 (high $\psi_{m}$ ),-0.06 to -0.07 (medium $\psi_{m}$ ), and -0.09 to -0.1 (low $\left.\psi_{m}\right) \mathrm{MPa}$, respectively, and then brought back to saturation. Temperature was $20^{\circ} \mathrm{C}$ in every treatment. Values are means of three experiments. Columns with the same letters are not significantly different from each other as determined by Duncan's multiple range test $(P=0.05)$.

Table 4. Orthogonal contrasts of four matric potential fluctuation treatments for mean numbers of apothecia of Sclerotinia sclerotiorum

\begin{tabular}{lccc}
\hline Orthogonal contrast $^{\text {a }}$ & MS & $\boldsymbol{F}$ value & $\boldsymbol{P} \boldsymbol{F}$ \\
\hline Saturation or low vs. medium or high & 198.1 & 20.6 & 0.01 \\
Saturation vs. medium & $22,816.7$ & 6.82 & 0.03 \\
Saturation vs. high & 24,832 & 7.43 & 0.02 \\
\hline
\end{tabular}

a Low, medium, and high soil water potential fluctuation treatments were generated by drying sand from saturation for 3,5 , and 7 days until soil water matric potential $\left(\psi_{m}\right)$ reached -0.03 to -0.04 (high $\psi_{m}$ ), -0.06 to -0.07 (medium $\psi_{m}$ ), and -0.09 to -0.1 (low $\psi_{m}$ ) $\mathrm{MPa}$, respectively, and then brought back to saturation. Temperature was $20^{\circ} \mathrm{C}$ in every treatment. a previous study (23) showed the optimum temperature for carpogenic germination of sclerotia to be around $20^{\circ} \mathrm{C}$ whereas, under a lower light intensity (110 to $120 \mathrm{~mol} \mathrm{~m}^{-2}$ $\mathrm{s}^{-1}$ at the level of the crisper cover), the optimum temperature was 12 to $18^{\circ} \mathrm{C}$. Therefore, we speculate that light intensity could have affected the results of our study. It is possible that a higher frequency of carpogenic germination under 12 or $16^{\circ} \mathrm{C}$ temperature fluctuations than the one found in the current study could have occurred had light intensities been lower.

Sclerotia are distributed differently in the soil profile under different tillage regimes. Newly formed sclerotia fall to the ground from infected soybean stems and remain on the soil surface in no-tillage fields, or are buried in the upper 5 to 10 or 10 to $20 \mathrm{~cm}$ in reduced-tillage and plowed fields, respectively (15). Gracia-Garza et al. (9) observed a greater number of apothecia with reduced tillage than no tillage, and suggested that the higher soil moisture and nutrient availability and the lower soil temperature observed in reduced tillage compared with no tillage could trigger this. Our study suggests that this hypothesis was correct. Whereas, in our experiments, sclerotia were placed on the sand surface, in reduced tillage most sclerotia are buried in the upper 5 to $10 \mathrm{~cm}$. Shallow burial of sclerotia could generate more interaction effects among sclerotia, soil, and soil microorganisms, with unforeseen outcomes.

A frequent recommendation for Sclerotinia stem rot management calls for reduction of soilborne inoculum (i.e., sclerotia) through crop rotation. However, sclerotia may remain viable in the soil for several years (1) and, thus, a long-term rotation is necessary for inoculum reduction. Alternatively, avoidance of tillage and use of wide row spacing may be management options, especially in cases in which long-term rotation is not feasible. Under these management options, temperature and soil moisture are likely to fluctuate widely, allowing only low numbers of apothecia to be produced late in the season, during flowering, when most infections by $S$. sclerotiorum occur. With the large portion of soybean-producing areas in the north-central United States being under no tillage, it appears that the implementation of wide row spacing would be an important measure for successful management of Sclerotinia stem rot in soybean fields with a history of the disease.

\section{ACKNOWLEDGMENTS}

We thank L. Tiffany and G. P. Munkvold at Iowa State University for assistance in the identification of the fungal species, and M. Gleason and B. Teviotdale for critically reviewing the manuscript.

\section{LITERATURE CITED}

1. Abawi, G. S., and Grogan, R. G. 1975. Source of primary inoculum and effects of temperature and moisture on infection of beans by Whetzelinia sclerotiorum. Phytopathology 65:300-309. 
2. Abawi, G. S., and Grogan, R. G. 1979. Epidemiology of diseases caused by Sclerotinia species. Phytopathology 69:899-904.

3. Boland, G. J., and Hall, R. 1988. Epidemiology of Sclerotinia stem rot of soybean in Ontario. Phytopathology 78:1241-1245.

4. Buchan, G. D. 2001. Soil temperature regime. Pages 45-58 in: Soil and Environmental Analysis. K. A. Smith and C. E. Mullins, eds. Marcel Dekker Inc., New York.

5. Butzler, T. M., Bailey, J., and Beute, M. K. 1998. Integrated management of Sclerotinia blight in peanut: utilizing canopy morphology, mechanical pruning, and fungicide timing. Plant Dis. 82:1312-1318.

6. Campbell, G. S. 1977. An Introduction to Environmental Biophysics. Springer-Verlag, Berlin.

7. Doran, J. W. 1980. Microbial changes associated with residue management with reduced tillage. Soil Sci. Soc. Am. J. 44:518-524.

8. Duniway, J. M., Abawi, G. S., and Steadman, J. R. 1977. Influence of soil moisture on the production of apothecia by sclerotia of Whetzelinia sclerotiorum (Abstr.). Proc. Am. Phytopathol. Soc. 4:115.

9. Gracia-Garza, J. A., Boland, G. J., and Vyn, T. J. 2002. Influence of crop rotation and reduced tillage on white mold of soybean caused by Sclerotinia sclerotiorum. Can. J. Plant Pathol. 24:115-121.

10. Grau, C. R. 1989. Sclerotinia stem rot. Pages
47-48 in: Compendium of Soybean Diseases, 3rd ed. J. B. Sinclair, and P. A. Backman eds. American Phytopathological Society, St. Paul, $\mathrm{MN}$.

11. Grau, C. R., Radke, V. L., and Gillespie, F. L. 1982. Resistance of soybean cultivars to Sclerotinia sclerotiorum. Plant Dis. 66:506-508.

12. Hao, J. J., Subbarao, K. V., and Duniway, J. M. 2003. Germination of Sclerotinia minor and $S$. sclerotiorum sclerotia under various soil moisture and temperature combinations. Phytopathology 93:443-450.

13. Hartill, W. F. T. 1980. Aerobiology of Sclerotinia sclerotiorum and Botrytis cinerea spores in New Zealand tobacco crops. N. Z. J. Agric. Res. 23:25-262.

14. Kora, C, McDonald, M. R., and Boland, G. J. 2005. Lateral clipping of canopy influences the microclimate and development of apothecia of Sclerotinia sclerotiorum in carrots. Plant Dis. 89:549-557.

15. Kurle, J. E., Grau, C. R., Oplinger, E. S., and Mengistu, A. 2001. Tillage, crop sequence, and cultivar effects on Sclerotinia stem rot incidence and yield in soybean. Agron. J. 93:973982.

16. Matheron, M. E., and Porchas, M. 2005. Influence of soil temperature and moisture on eruptive germination and viability of sclerotia of Sclerotinia minor and S. sclerotiorum. Plant Dis. 89:50-54.

17. Morrall, R. A. A. 1977. A preliminary study of the influence of water potential on sclerotium germination in Sclerotinia sclerotiorum. Can. J. Bot. 55:8-11.

18. Phillips, A. J. L.1987. Carpogenic germination of sclerotia of Sclerotinia sclerotiorum: a review. Phytophylactica 19:279-283.

19. Purdy, L. H. 1979. Sclerotinia sclerotiorum: disease and symptomatology, host range, geographic distribution, and impact. Phytopathology 69:875-880.

20. Schwartz, H. F., and Steadman, J. R. 1978 Factors affecting sclerotium populations of and apothecium production by Sclerotinia sclerotiorum. Phytopathology 68:383-388.

21. Steadman, J. R., Coyne, D. P., and Cook, G. E. 1973. Reduction of severity of white mold disease on Great Northern beans by wider row spacing and determinate plant growth habit. Plant Dis. Rep. 57:1070-1071.

22. Sule, R. M., and Rhodes, L. H. 1997. Planting date, fungicide, and cultivar effect on Sclerotinia crown and stem rot severity in alfalfa. Plant Dis.81:13-17.

23. Sun, P., and Yang, X. B. 2000. Light, temperature, and moisture effects on apothecium production of Sclerotinia sclerotiorum. Plant Dis. 84:1287-1293.

24. Workneh, F., and Yang, X. B. 2000. Prevalence of Sclerotinia stem rot of soybean in northcentral United States in relation to tillage, climate, and latitudinal positions. Phytopathology 90:1375-1382. 